IN3 Working Paper Series INTERNET INTERDISCIPLINARY INSTITUTE

\title{
Authenticity on Facebook Between Exposure and Self Representation
}

Greti-Iulia IVANA (igreti_iulia@uoc.edu) Universitat Oberta de Catalunya

\section{Doctoral Working Paper}

Doctoral Working Paper Series DWP14-007

Research group: Grup d'Estudis en Cultura i Societat

Research group coordinator: Roger Martínez Sanmartí (Universitat Oberta de Catalunya)

Submitted in: September 2014

Accepted in: November 2014

Published in: November 2014
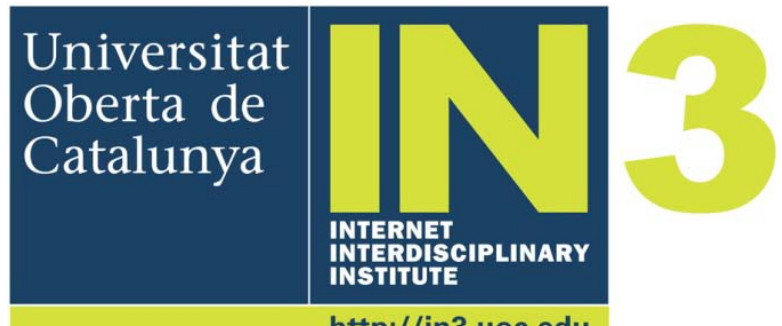


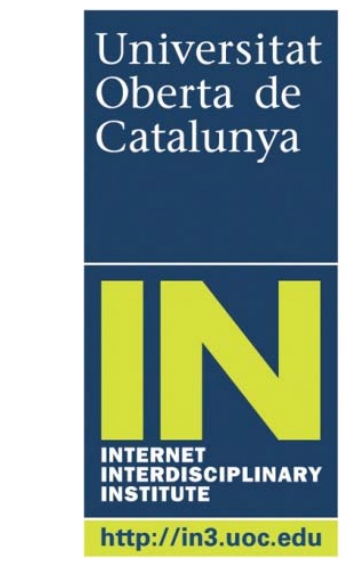

Internet Interdisciplinary Institute (IN3)

http://www.in3.uoc.edu

Edifici MediaTIC

c/ Roc Boronat, 117

08018 Barcelona

Espanya

Tel. 934505200

Universitat Oberta de Catalunya (UOC)

http://www.uoc.edu/

Av. Tibidabo, 39-43

08035 Barcelona

Espanya

Tel. 932532300

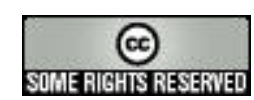

The texts published in this publication are - unless indicated otherwise - covered by the Creative Commons Spain Attribution-Non commercial-No derivative works 3.0 licence. You may copy, distribute, transmit and broadcast provided that you attribute it (authorship, publication name, publisher) in the manner specified by the author(s) or licensor(s).

The full text of the licence can be consulted here:

http://creativecommons.org/licenses/by-nc-nd/3.0/es/deed.en. 


\section{Table of contents}

Abstract

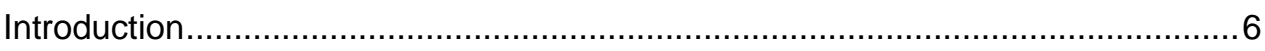

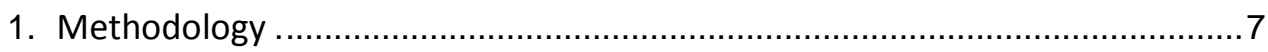

2. Rethinking self presentation on social networking sites. .............................. 8

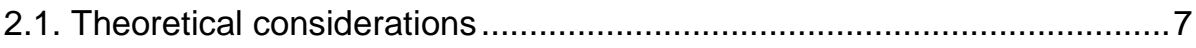

2.2. User's perspective on exposure and authenticity...................... 9

3. Questioning the Unity of Symbolic Hierarchies.............................................

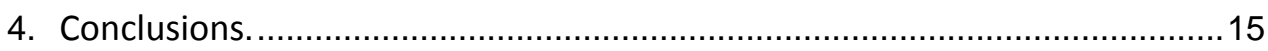

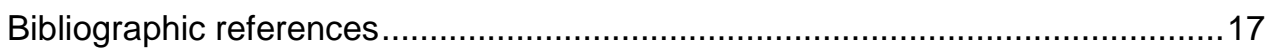




\section{Authenticity on Facebook Between Exposure and Self Representation}

Greti-Iulia IVANA (igreti_iulia@uoc.edu)

Universitat Oberta de Catalunya

\section{Recommended citation:}

Ivana, Greti-Iulia (2014). "Authenticity on Facebook. Between Exposure and Self Representation" [online working paper]. (Working Paper Series; DWP14-007). IN3 Working Paper Series. IN3 (UOC). [Accessed: dd/mm/yy].

$<$ http://journals.uoc.edu/ojs/index.php/in3-working-paper-series/article/view/n14-gretiiulia/n14-greti-iulia> 


\begin{abstract}
The aim of this paper is to explore the topic of self presentation on Facebook, by rethinking Goffman's dramaturgy of everyday life and adapting it to the environment of social networking sites. In order to do so, I draw on two existing discussions in the literature: one is the dichotomy between self presentation and exposure (with users shifting between being subjects and objects) and the other is the increased preoccupation with representation rather than presentation of the self, which is specific to late modernity. My understanding of the issue comes from a qualitative empirical study, with data consisting of semi structured interviews with Facebook users. The conclusion, drawing on Featherstone, is that the interpretative processes which come into play when reading Facebook posts as presentation, representation or exposure, have lost their uniformity with the rise of multiple competing regimes of significance.
\end{abstract}

\title{
Keywords
}

self, exposure, presentation, representation, authenticity. 


\section{Introduction}

This article proposes an analysis of the link between two concepts that are often used both in scholarly work and in everyday life in relation to social networking sites and especially Facebook. One of them is the presentation of the self from Goffman's dramaturgical perspective, which emphasizes social roles, expectations, norms and contexts. The other is the concern with the authenticity of that which is presented in the network, the extent to which the contents reflect users' true beliefs, emotions, and tastes. So, the question I set out to answer is the following:

- How do Facebook users manage their self presentation in a way that harmonizes their understandings about social roles and performativity with the emphasis they themselves as well as the ones around them place on authenticity?

I have chosen Facebook to talk about the articulation of social norms and authenticity because Facebook (and especially the public side of it, on which I am insisting) is an environment where interaction is typically asynchronous and lacking flow. Consequently, the design of the platform allows users the time and privacy to (inter)act in ways they believe are consistent with the image they wish to project. While this also happens in offline social situations, on Facebook the reflective component of the process is underlined and easier to trace back even by the actors themselves. Someone can almost effortlessly remember what they thought when they commented on another's public status update (also because the outcome of the action is stocked and accessible at all times), than it is to remember what their spontaneous reply was in a face to face interaction and what triggered that reply. Furthermore, Facebook offers each user a certain space where all past public actions are registered. This favors an increased awareness about the self as a whole and encourages a perspective in which each action or interaction is primarily seen in relation to that whole on a very explicit level. At the same time, the disembodiment of the social actors involved, creates a sense of insecurity in "reading" what the other is expressing, which leads to doubts about authenticity. The term disembodiment is used in the sense proposed by Slater (2002, p. 536) and signifies that "a person's online identity is apparently separate from their physical presence". He associates this with textuality and anonymity. His definition still stands for the case of Facebook, with the amendment that anonymity is no longer part of the typical practice. Going back to the main argument, the features of 
the platform as well as the disembodiment inherent to online communication make Facebook public actions and interactions a very suitable source of empirical data in a discussion about social roles in self presentation and their relation to authenticity.

\section{Methodology}

In order to explore this question, my methodological tools are the ones specific to qualitative social research, and, more specifically grounded theory. Based on works such as Glaser and Strauss (1967) and Strauss and Corbin (1990, 1994), I focus on producing social theory on the foundation of existing work in the field, but mostly focusing on drawing conclusions from the analysis of the empirical data. Among other advantages, this methodological route allows for the opinions and concerns of those who are researched to be assimilated in the construction of the theoretical discourse. With respect to the practical component of the data gathering, I have conducted a series of 40 semi-structured interviews with Facebook users. The interviews were conducted face to face in Barcelona and Cluj Napoca. The users were people aged 18 and over, who had Facebook profiles, who logged in daily and who posted at least one piece of content since they joined the network. They were ethnically diverse (Spanish, Catalan, Romanian, Swedish, Brazilian, Norwegian, Russian, Mexican, American, British). The interviews were conducted in English, Romanian and Spanish. This sample has been chosen due to a series of reasons. Firstly, when investigating the articulation of social norms and authenticity in the self presentation of the users, it was important to interview people who connect to Facebook often enough that they are familiar with the platform and who already have an account of what are typical and atypical actions, what contents the others expect to see and what they could/should/ want to share. In this sense, logging in daily was a crucial condition for choosing the sample. Secondly, people who only monitor the activity of the others already have a sense of how self presentation on Facebook works. However, I believe the users who have also shared something with the others have a deeper understanding of the experience, the thought process, the emotions involved in deciding to publicly post certain contents or in receiving feedback. Thirdly, due to the symbolic interactionist perspective I am using, my focus is on how small scale negotiations and rituals are involved self expression and in social interactions, rather than on the specific social norms or expectations held by each interviewee. The emphasis is on the process of self presentation and the interactions around it, not on a given set of social rules or expectations. That is why macro social indicators of large scale patterns (ethnicity, levels of education, gender) were not included in the sampling. Last but not least, since the gathering of the data involved open ended interviews (with an average time of over 
an hour) the sample is, from this point of view, one of convenience, because it consisted of users who agreed to offer their time to talk openly and to be recorded.

The themes on which I insisted were the behaviors of the users (routines, examples of things they posted or reactions they had on others' posts, chatting habits), the ways in which they constructed meaning for the others' post and expected their own would be interpreted, and some memorable, emotional or notable experiences they had on Facebook.

\section{Rethinking self presentation on social networking sites}

\subsection{Theoretical considerations}

Having decided to approach the theme of self presentation, I have found myself, as probably many sociologists do, unable to take any sort of distance from the very strong influence that Goffman has established. Concepts of front stage, back stage, actor, role or dramaturgy immediately came to mind. While avoiding them is definitely unproductive, shedding new light on them is not an easy task, given Goffman's own sensitivity to detail and variation. However, one of the strongest critiques that have been raised in relation to Goffman's work is the lack of consideration for both the large scale situations in which self presentation occurs and the actual content of social interactions. Blumer, who is widely regarded as one of the founding figures of symbolic interactionism, notes: "He confined the study of face-toface association to the interplay of personal positioning at the cost of ignoring what the participants are doing." (Blumer 1972, p. 51). I believe this critique to be well documented, but it does not constitute an insurmountable obstacle in using some of Goffman's insights in a productive way. Namely, a solution for overcoming the emptiness of the interactions depicted by Goffman, as well as their isolation from the rest of the social world is a stronger emphasis on the emotional component of human behavior. As Sara Ahmed (2004, p.4) puts it, "attending to emotions might show us how all actions are reactions, in the sense that what we do is shaped by the contact we have with the others." Under this lens, the level of formalization specific to the dramaturgical approach decreases inherently. Moreover, following Parkinson (1995, pg. 8) I argue that emotions are always directed towards an object, and in order for 
them to occur, certain meaning has to be attributed to the object, the context and ultimately the world.

A legitimate point one might make at this stage is that the concept of emotion is known to be present throughout Goffman's work. Not only that, but he is also one of the earliest analysts of emotion in sociology. In his essays on face, Goffman talks about shame, humiliation, pride, honor, appreciation or embarrassment. However, I consider all these to fall into the category of what Sennett (1974) calls presentation of emotion, rather than representation of it. They are emotions embedded in the dramaturgy of everyday life, they are emotions directly linked to the existence of an audience/collectivity and to its evaluations of the actor/subject. Comparing these with Sennett's example about the emotions felt by the subject over someone's death, it is clear that the latter is less linked to a social response, which is not to say it is not social in essence (although Sennett sees it as asocial, which I will come back to later). Sennett himself talks about the presentation of the self, about roles and the dramaturgy of everyday life. He points out the importance of putting on a believable performance, as well as the continuity of the content presented. But it is not simply the continuity of what is being expressed that matters. The way an actor talks, moves, behaves makes him credible or not, irrespective of what is known about him, and that, he claims, is as true for everyday life as it is for the theatrical world. In this respect, his analysis of self presentation is very similar to Goffman's. However, unlike Goffman, he identifies a historical change started in the $19^{\text {th }}$ century, a shift from the above mentioned self presentation to representation. Drawing from Sartre and Trilling, Sennett points out that in the last couple of centuries self disclosure and feeling genuinely has come to be more important than the content of what is felt. The concept of representation of the self certainly allows for more space of discussing about emotions, as it solves the issue of uniformization of emotions and liberates the actor from his role.

Since Sennett is not very explicit about what he understands by being genuine or by the concept of authenticity, I will insist for a moment on what authenticity is in my own reading of Sennett (1974). I believe his theory about the representation of emotions employs authenticity in the sense described by Turner and Schutte(1981), namely as the experience of feeling congruent to one's sense of true self, or feeling true to one's ideal self. As Vannini and Williams (2009, p.7) point out, what matters is what one feels as being authentic or not. But even assuming authenticity is not based on socially determined values (which is hard to believe, one of the many counterarguments being that it involves an ideal self, which is socially constructed), authenticity is a value in itself and thus, needs to be assessed. It is, as Van Leeuwen (2001, p.392) puts it, an evaluative concept. This is, thus, the sense in which I will use the notion of authenticity.

So, bearing all these in mind, the question is how do presentation and representation of the self coexist on social networking sites and especially Facebook? What is the importance given to authenticity (or claims of authenticity) and to what is 
the network seen as another vehicle for presentation according to a pattern of readable emotions and reactions?

By SNS's I mean sites defined by combination of features that allow individuals to (1) construct a public or semi- public profile within a bounded system, (2) articulate a list of other users with whom they share a connection, and (3) view and traverse their list of connections and those made by others within the system (boyd \& Ellison, 2007).

One of the earliest attempts of linking the online environment with authenticity is Slater's (2002). At that time, Slater was posing the following question: "On what basis should one believe that anyone online is who they claim to be; and can relationships that are plagued by this degree of doubt be treated as serious and 'real' relationships?" (Slater 2002, p. 536). Given the design of social networking sites and particularly Facebook, where the other is typically already linked with the subject in the offline as well as the online, part of that question has been answered. However, on a more subtle level, doubts still persist, not the name, the gender or the race of the other (as in Slater's text), but about their honesty, their intentions, their expectations when sharing something.

A common idea of articles about SNS's is that individuals use this tool to employ impression management (or the selective disclosure of personal details designed to present an idealized self). As I noted in the beginning of the article, Goffman has often been used as a theoretical framework for the study of SNS's, but his insights have been frequently applied in a very unproblematized manner.

An exception to this tendency is Hogan's (2008) writing on the exhibitional approach which, although it also elaborates on Goffman's work, it questions it as well. Hogan states that on social networking sites what we are dealing with is not presentation, but exposure of the self, since self presentation is based on the presence of others and adaptation of behaviour so that it matches the expectations of the audience. Original performances are dependent upon context, while recorded ones can be played in any setting. Consequently, he considers profiles to be reproductions of the self, which lack the aura of the original. Thus, he believes users to be not actors, but artefacts. However, in light of Sennett's writings on self presentation and self representation, another way of interpreting the lack of concern for context that appears on Facebook, not as a process of transforming users into artifacts, but as a mere consequence of the fact that users have assimilated the tendency of valuing personal emotions and authenticity and have come to be less interested in standardization emanating from the expectations of the audience. In other words, it can be regarded a shift not from actor to artifact, but from actor to agent.

If manifesting one's own genuine emotions and ideas is the main focus when having a profile, it follows that this form of self representation is not depended upon communicating with an audience or upon what anyone wants to see. Representation, just like exposure, is not calibrated on the audience, it is not about giving and receiving and it doesn't have to even be intelligible for the others. But, if Hogan doesn't talk 
about the criteria that validate exposure in front of the others, Sennett does talk about it in relation to representation, and that validation comes from authenticity. As long as that which is shared is genuine, it is valued, Sennett claims, regardless of content. I believe this to be the case on Facebook and the fieldwork supports this assumption. An opposite claim is made Uski and Lampinen (2014), who argue that authenticity itself is perfomative. They propose the expression "presentation of authenticity" and they explain their position as it follows: "In stark contrast to the way authenticity is popularly understood as something straightforwardly true and unintentional, our study makes apparent how authenticity is ascribed, constituent (Van Zoonen, 2013: 46). Authenticity is an intentional presentation that is given for others to see and appreciate." (Uski and Lampinen 2014, p. 15)

From a different perspective, Scannell (2001, p. 410) makes a distinction between the authenticity of experience of own-self and they-self, where they-self is the one that makes the social possible, because it regards the own self as being anyone else in possibility. In my understanding, although this distinction succeeds in pointing out a dimension of social transferability, it creates an artificial distinction, where, in fact the own self and the social "they self" are continuous and inseparable.

\subsection{User's perspective on exposure and authenticity}

The interviewees have constantly talked about issues of fakeness, creating a certain image, spontaneity, contradictions between one's own impression of another and that other person's profile, which is often taken as a clue of lack of authenticity.

When asked about what he finds striking on Facebook, this is what one of the respondents has said:

"There are people who try to display a small part of themselves on Facebook only to look better. Like a girl I met in the hostel in my first week here. I saw her, she was there all the time, never left, never did anything fun or exciting. To me, she was a very boring person. And very lazy too. She said she also wanted a job, but I don't think she applied looked for more than 4 or 5 . And when I went on her Facebook profile, it turns out she had been on vacation recently and she posted pictures. All of them were from very interesting places, she was smiling, she commented about how much fun she had. And she was not like that at all.(..) I think she is very insecure and wants to show everyone that she is great and has a wonderful life. But you know, with people's online presence, it's like the two faces from Batman. If you see them from that 
perspective, they look normal and nice. But if you see them from the other side, or from the front, you're like "wow, this is really messed up" (Sb2, male, 22)

The interviewee points out the contradictions between one's online display and his own impression about the person in question. He opposes her less than exciting personality, her laziness to the fun loving and open image that she promotes and he concludes in an implacable manner: "she was not like that at all". It seems in this case that he values self representation and blames her for doing a mere self presentation. Just like in Sennett's example about expressing emotions over someone's death, what is done through presentation is "selecting some details to emphasize, suppressing others, even falsifying his report, in order to fit it into a form or fit a pattern which his listener understood to be what dying was about." (Sennett 1974, p. 107) The girl the interviewee was referring to wanted to fit the pattern she assumed the viewers of her profile had for assessing the greatness of one's life, by selecting certain details from her experiences and omitting others. And her assessment was accurate, at least in the case of the viewer I was interviewing. He considered the profile to show a desirable lifestyle. He just didn't find it convincing.

Secondly, what I also find very interesting in this quotation is the reference to the two faces from Batman. What I believe needs to be noted is that my interviewee was not talking about acting or about a mask, but he was talking about perspectives. The two faces are in fact two sides, both as real, of the same person. Thus, when selecting this statement I wondered if the interviewee's complains are indeed reflected in the concepts of presentation and representation. In my interpretation, the essence of the comparison is that in showing only a desirable side, one is leaving out precisely the aspects they believe will affect their overall image. And that is what, if I understood correctly, the interviewee is referring to when he mentions "seeing them from the front". Although the pleasing side is there, putting it into the context of the entire face constructs a different entity altogether. This is particularly relevant, since the seen side is presented from an angle that encourages a certain imaginary to be constructed about the unseen side as well. That, I think, is why he affirmed she is not like that at all. Thus the image displayed is not authentic.

Another instance where I have noticed issues of presentation and representation being recurrently brought up is the spontaneity and naturalness of pictures. As an illustration, one interviewee stated:

"There is this girl I know and she's studying Egyptology in the US and every day she is posting photos about her research and she is studying the things I kind of like. And I like more this kind of photos, like with her desk or her books, than the ones where you are kind of like... (mimics a forced smile). (...)It's ok for people standing to have their pictures taken if it has to do with a trip, but I prefer the casual things. Like once I went out on my balcony and there were 2 pigeons there, really close, like kissing. Birds don't kiss (I think), but 
that was a nice picture, so I took it and I uploaded it to Facebook, because it was something of the moment and a casual thing. But I don't think of me as going to my mother, or my friend or my brother and saying "hey, please take me a photo with today's outfit!" No!" (Sb10, female, 25)

This interviewee finds joy in the preoccupations of the person who posts, in the events that are evoked and dislikes very thought through images, hence the reference to asking someone to take a picture of yourself when you are happy with your look. This, in my interpretation, is a view rooted in the concern for authenticity in self representation. The type of control over what is expressed (resulting from choosing clothes or showing a smile) is, again typical of performances meant to met the criteria of an audience. They are self presentation. However, standing in what would seem like a planned picture becomes acceptable when it is on a trip. I believe this is because it relates to an event that goes beyond the purpose of simple presentation. It becomes sharing, it becomes an experience lived by the people in the picture. It is, thus, considered genuine and embraced. One other interviewee has even openly affirmed that he feels he needs to be represented by his profile:

"I am not a very emotional person, so therefore my Facebook account to a certain extent reflects my personality, it reflects who I am. Since I don't like fake people, I am not gonna have a fake Facebook account."(Sb6, male, 30)

However, although I believe Sennett's account for self presentation and representation to fit Facebook profiles better than Hogan's Goffman-based theories about self presentation and exposure, there is a certain point that needs to be made. Sennett, following Rousseau sees self representation as entirely asocial.

Representation as expression of self is characterized by the emphasis on the individual experiences and lack of standardization or hierarchies. No representation is more desirable or more appreciable that another in itself, but it only gains value through proving its own authenticity. On the other hand, for presentation to function, a set of common codes of believability has to be in place. Sennett states that these codes result in a public geography, which is conditioned by two factors. The first is that the world external to immediate surroundings becomes consciously defined. The second is that movement through social circumstances with strangers is comfortable due to these codes. I believe that representation as self expression, as original at it might be, also needs certain common codes in order to exist. Although there is a certain consciousness about the uniqueness of each individual, that very uniqueness is grasped based on relating it to one's own self. Without common codes it is impossible to maintain one's otherness readable, let alone meaningful. And although Sennett proclaims the principle of representation of emotion as asocial, emotional bonds are nevertheless being created somehow. 
When asked about how he feels about emotional status updates, one of the interviewees affirmed:

"Depends on the case. It also depends on... for example if someone says: "Oh! I got robbed in the street! They took my wallet!" I think that is a valid expression of feelings, because something happened to you. If it's something that is actually worth mentioning, I don't think it's funny. I think it's more like: "Dude, are you ok?" But if it's something like "life sucks bla bla bla", so attention seeking, I make so much fun of it."(Sb15, male, 27)

So, the authenticity itself is evaluated according to what the other can relate to. The feelings that are triggered by being robbed are something he is familiar with and he understands. On the other hand, the emotions that he cannot link to a certain experience or that he has no clues about how to read, he simply rejects as inauthentic and amusing.

Furthermore, my assumption is that presentation has not been replaced, but rather reinforced by representation. Society does not value genuine self expression irrespective of any standardized norms, but it values the interiorization of the standards to the degree that makes the expression authentic, and, at the same time, compatible with the common understanding. (Of course, it is difficult to discuss common understandings monolithically, but that does not affect this argument.) Self representation, as described by Rousseau and Sennett, implies a fiction of self in a social void. Social reality is still very strongly anchored in concepts of acceptability or normality, even in the areas that are regarded as the most "liberated", such as the emotional sphere. The context that Sennett himself has identified as having triggered the emergence of representation can also be viewed in this light. The curiosity about the stranger's character was justified by the need to confirm the person's truthfulness to what he publicly stood for. So it was not making sure one is authentic in whichever beliefs they have, but that they are authentic in their conformity. That is why I argue that, although at one level representation and the preoccupation with individuality, with the self are key elements of managing a Facebook profile, at another level the issue of common codes is still very present and needs to be taken into account. Moreover Facebook is, in my understanding, a place where these codes are very well isolated and easy to pin down, since communication is scarce and lacking flow.

In order to support these thoughts, I am coming back to what the subjects say about their experience with presenting and representing emotions. Somehow surprisingly, after having explained how much they valued authenticity and disliked the others' attempts to put things in a favorable light, many of them admitted to having a great deal of care for the image they project. One respondent, for example, mentioned:

"I might go a bit off topic here, but on Facebook, what people post is what they think is interesting or remarkable and no one is doing remarkable things all the time. You do plenty of boring things all day long (...). When I am at work, I don't update Facebook: "I am 
at work! Hooray! I am filling Excel sheets!" That is boring. I do that (note: show off) and I think that is what everyone does. You try to make yourself interesting." (Sb15, male, 27)

Consequently, no matter how strong the tendency for representation of emotions described by Sennett has become, it has only overlapped on a fundament of social codes without undermining them. If for no other reason, social appraisal, the audience, are still important in selecting what to share and what not to. Being boring or being interesting has nothing to do with how genuine one is in their expression. It has, however, everything to do with self presentation. The selection is made according to the user's understanding of the expectations the viewers have. Only because an expression is authentic, it doesn't necessarily qualify it as shareable. There is nothing fake in filling Excel sheets or in expressing certain emotions about that, but contrary to Sennett's theory, this user limits the representation of himself to the occasions when he is doing something special or remarkable, or, in other words, something that is also higher on a social scale. And in many cases, one's own evaluations correspond with the reactions of the "audience". For instance:

"Hm, almost every time I pick or I choose the picture that I think the best (laughs), or I look like pretty. Sometimes, I have intentionally chosen pictures where I looked really bad. (...) For me it is really an experiment. Because almost all the people choose pictures where they look fine or pretty or intelligent or whatever, so once I made an experiment and I choose one picture where I really looked bad(...)Most of the people commented on the pictures where I looked fine, they liked it or made a comment, saying "you look gorgeous" or "you're pretty". On that occasion, when I chose the bad one, they refused commenting. They preferred not to comment and to tell me in real life "What are you doing?" "Why did you choose that picture?", but they didn't comment, they told me in real life."(Sb5, female, 25)

This I consider a very clear example of how codes function. The friends of my interviewee didn't just assume the picture to be a genuine form of self expression, or they did, but they nevertheless deemed it unusual. It was a step away from the script of what is typically transmitted through Facebook, which means a certain degree of standardization exists. Secondly, the fact that the comments were not made on Facebook is also significant. Since they were also very aware of the value the audience's response typically has, they made an attempt at fixing the presentation without making it public.

So, the post has to be authentic, but at the same time it has to be well looked upon. However, there is variation, from one respondent to the other in respect to which is predominant. Most say they would post something they feel strongly about even if they suspected it would be disapproved by all of their friends. Yet, none of them has 
ever felt the temptation to do so, except for one who admitted he regretted it afterwards.

Another sign of the cultural shift from believing in presentation of emotion to believing in representation of it is, in Sennett's view, that fact that who speaks determines increasingly the expressiveness of what is said. Here, I come back to the argument above about the layered nature of representation and presentation. Although it is somewhat counterintuitive, since representation refers to an expression of a deeper self, I believe it precedes presentation. Who speaks is not more important that what is being said, it just needs to be established before, so that what is being said can be evaluated. This also applies on Facebook. Users look at what is being posted, they stop, they read the articles, and they listen to the music, as long as they know who posted it. Once a person has gained credibility, the content itself is evaluated and codes start being employed. Conversely, once a person has lost credibility, once the representation has been classified as in-authentic (which usually happens based on inconsistencies), what is being said is not relevant anymore.

\section{Questioning the unity of symbolic hierarchies}

But if self presentation is still very strong and coexists with the newer established practice of representation of emotions, why has Sennett proclaimed it dead? I believe the reason for his claim about the decreasing importance of codes and standardization is influenced by what is in fact the demonopolization of power from the old hierarchies of significance, which Featherstone (2007, p. 104) is talking about. The potential in terms of cultural capital that certain practices or objects have acquired, the blurring of the borders between culture in the anthropological sense and high culture have made symbolic hierarchies less crystallized. Thus, a certain behavior or a manifestation of emotion can be viewed as completely unrelated to a pre-established social expectation and be interpreted as genuine representation of feelings. It can, at the same time, be very strongly rooted in a parallel system of meanings, according to which it has all the characteristics of self presentation. It has become increasingly difficult to establish whether actions are taken or feelings are expressed according to the expectations of the audience, because there is no such thing as the audience anymore. The distinction between what was acceptable and what not was significantly more clear-cut in the $17^{\text {th }}$ century than it is today. But in each of the co-existing systems of signification there are codes. Most of them are only functioning according to the values and meanings of one or two systems and when asked about others they affirm their only concern is not to be 
offensive to anyone; others try to find ways of accounting for two or more different systems of attribution of meaning at the same time:

"You suddenly find yourself having people that you are or have been in touch with in several of these subsystems in your life, all together in just one room. So when you publish something, they will all read it, they can all read it. Which means in my situation that you are completely blocked, because I am not the same person in all of these subsystems, so whenever I publish something, I know I will be punished by at least one of these subsystems." (Sb4, female, 35)

\section{Conclusions}

So, to conclude, this is an argument for the benefits of complimenting Goffman's dramaturgy of everyday life with perspectives on self realization and the larger scale tendency for increasing emphasis on genuine emotional expression. My aim has been to explore the ways in which Facebook users construct the articulation of these elements that seem contradictory, how they evaluate them and what meanings they construct around them.

\section{Bibliographic references}

Ahmed, Sara (2004). The Cultural Politics of Emotion. Edinburgh University Press.

Blumer, Herbert (1972). "Action vs. Inter-action: Review of 'Relations in Public' by Erving Goffman 1971", Society, vol. 9, pp. 50-53.

Boyd. d., \& N. Ellison (2007). "Social Network Sites: Definition, History, and Scholarship", Journal of Computer-Mediated Communication, Retrieved from: http://jcmc.indiana.edu/vol13/issue1/boyd.ellison.html

Featherstone, Mike (2007). Consumer Culture and Postmodernism. $2^{\text {nd }}$ edition. Sage Publications.

Glaser, Barney G. and Strauss, Anselm L. (1967). The Discovery of Grounded Theory: Strategies for Qualitative Research. Chicago: Aldine. 
Goffman, Erwin (1959). The presentation of the self in everyday life, New York, NY: Anchor Books

Goffman, Ervin (1967). Interaction Ritual: Essays on Face- to-Face Behavior, Anchor Books.

Hogan, Bernie (2010). The Presentation of Self in the Age of Social Media: Distinguishing Performances and Exhibitions Online, Bulletin of Science Technology, 30 (6), pp. 377-386.

Parkinson, Brian (1995). Ideas and realities of emotion. London: Routledge.

Scannell, Paddy (2001). Authenticity and Experience. Discourse Studies, 3 (4), pp. 405-411.

Sennett, Richard (1974). The Fall of the Public Man. Penguin Books.

Slater, Don (2002). Socfial Relationships and Identity Online and Offline. In: Lievrouw, Leah and Livingstone, Sonia, (eds.) Handbook of New Media: Social Shaping and Consequences of Icts. Sage Publications, London, UK, 533-546.

Strauss, L. Anselm and Corbin, Juliet (1990). Grounded Theory Research: Procedures, Canons, and Evalutive Criteria, Qualitative Sociology, 13 (1), pp. 3-21.

Strauss, L. Anselm and Corbin, Juliet (1994). Grounded Theory Methodology: an Overview. In Denzin, N.K. and Lincoln, Y.S. (Eds.), Handbook of Qualitative Research. Thousand Oaks, CA: Sage, pp.273-85.

Turner, Ralph, Schutte, Jerald (1981). The True Self method for Studying the SelfConception. Symbolic Interaction, vol. 4, pp. 1-20.

Uski, Suvi, Lampinen, Airi (2014). Social norms and self-presentation on social network sites: Profile work in action. New Media and Society, pp. 1-18. DOI: $10.1177 / 1461444814543164$

Van Leeuwen, Theo (2001)."What is Authenticity?" Discourse Studies, 3(4), pp. 392397.

Vannini, Phillip, Williams, J. Patrick (2009). Authenticity in Culture, Self and Society. In Vannini, Phillip, Williams, J. Patrick (Eds.), Authenticity in Culture, Self and Society,

Ashgate Publishing Limited, pp.1-21. 


\section{Greti-Iulia Ivana}

Igreti_iulia@uoc.edu

Information and Knowledge Society Phd. program

Open University of Catalonia

Greti-Iulia Ivana is a Phd. Student at the Internet Interdisciplinary Institute, within the Open University of Catalunya. The topic of her PhD. Thesis is: "Read me like an open (Face)book! A Social Phenomenological Approach to the Relation between Meaning Constructions on Facebook and the Construction of Ties between Users". She is part of the research group "Grup d'Estudis en Cultura $i$ Societat" and her thesis directors are dr. Natàlia Cantó Milà and dr. Martin Berg.

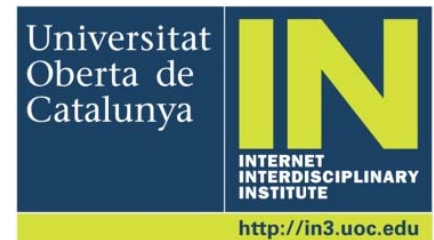

